Supplement of

\title{
Spectral- and size-resolved mass absorption efficiency of mineral dust aerosols in the shortwave spectrum: a simulation chamber study
}

Lorenzo Caponi et al.

Correspondence to: Paola Formenti (paola.formenti@lisa.u-pec.fr)

The copyright of individual parts of the supplement might differ from the CC BY 3.0 License. 
Figure S1. Linear deconvolutions of the XANES spectra obtained in this study

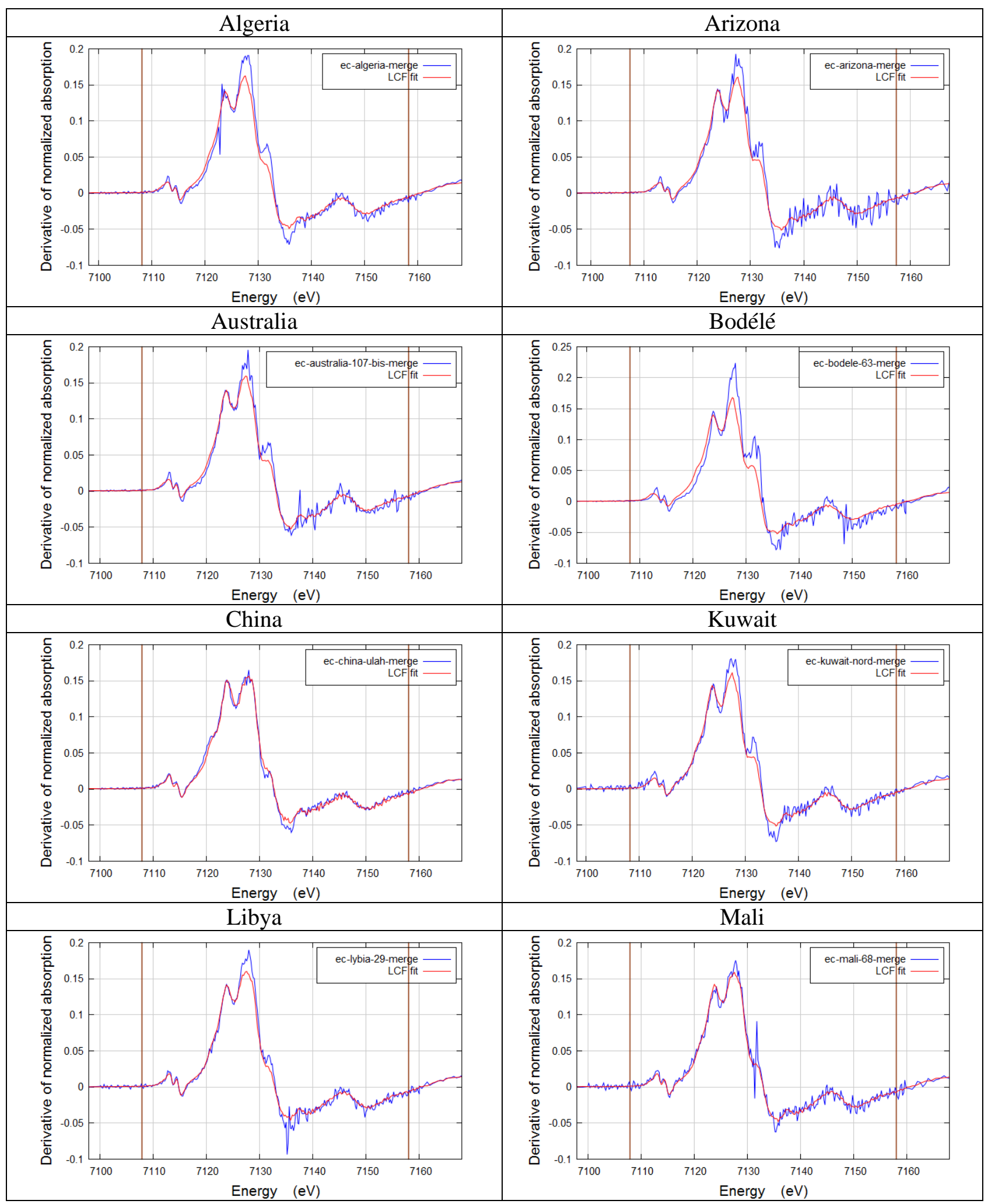




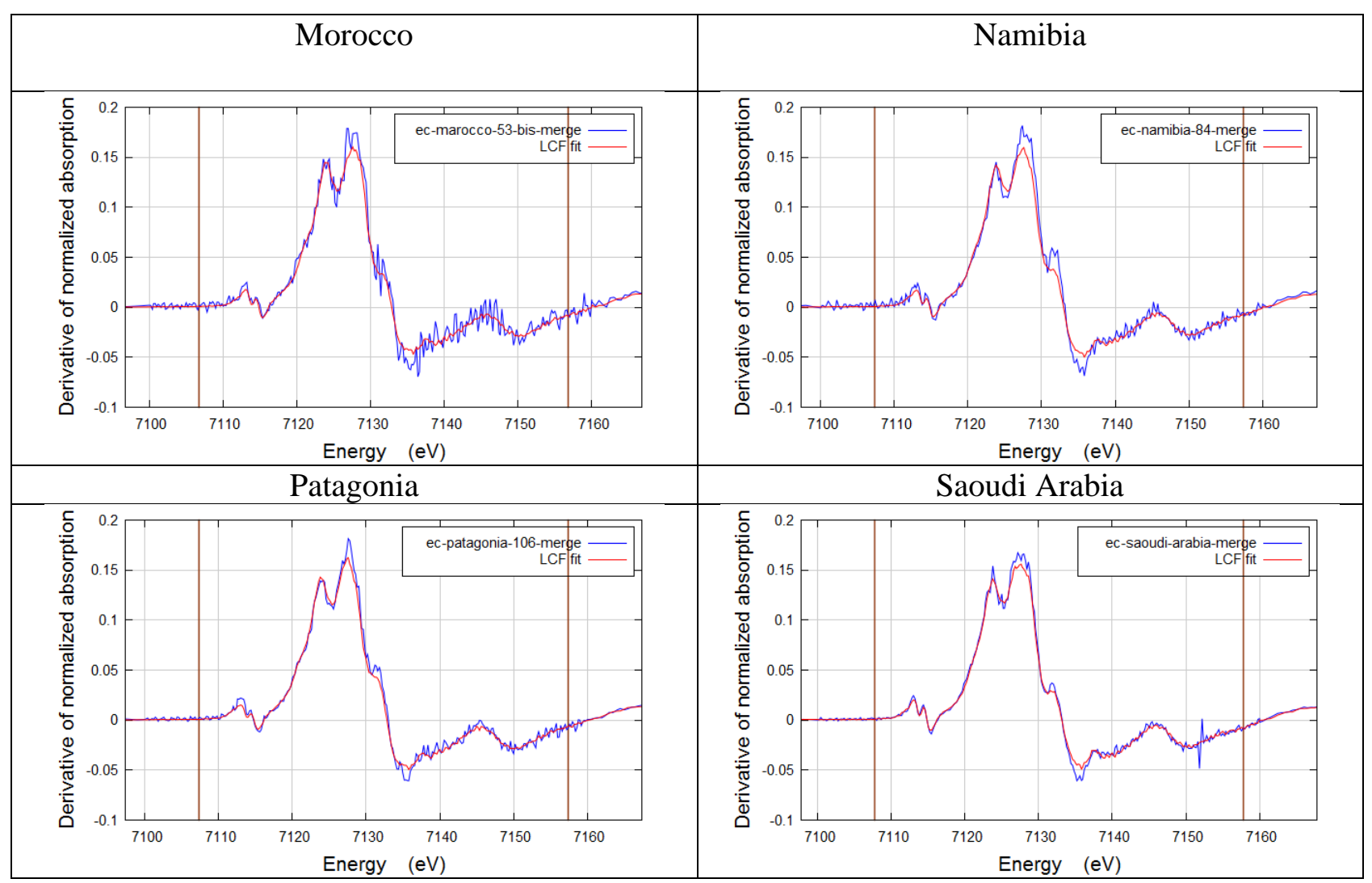

